\title{
La Zubia premia la labor de la científica Carmen Magallón con el Laurel de Plata
}

El pasado mes de agosto, la Dra. Carmen Magallón Portolés fue galardonada por el Festival Poesía en el Laurel, Granada, España, reconociendo su carrera como activista por la paz y los derechos de las mujeres.

Carmen Magallón ya se preguntaba hace 25 años por la historia de las mujeres científicas en España, lo que le llevó a escribir su tesis: Pioneras españolas en las ciencias. Las mujeres del Instituto Nacional de Física y Química.

La Doctora en Ciencias Físicas es ahora Presidenta de la Liga internacional de Mujeres por la Paz y la Libertad en España y exdirectora de la Fundación Seminario de Investigación para la Paz. El Festival Poesía en el Laurel premió su labor como activista por la paz y los derechos de las mujeres en los jardines del convento de San Luis el Real, haciéndole entrega del Laurel de Plata.

La catedrática de Física y Química está especializada en la historia de las mujeres en la ciencia, el análisis epistemológico del quehacer científico y las relaciones entre género, ciencia y cultura de paz.
En 2013, el Instituto de Investigaciones y Acción social Martin Luther King de la Universidad Politécnica de Nicaragua (UPOLI), condecoró a Magallón con la Orden de la Paz Martin Luther King upor su relevante contribución al desarrollo de los derechos de las mujeres, al pensamiento feminista y a la construcción de una cultura de paz en el mundorr.

La velada estuvo amenizada por los versos de María Sanz (España), Norberto Barleand (Argentina), Moez Akaichi Túnez) y Porfirio Salazar (Panamá). La concertista de piano Norah Wanton y el cantante Juan Valderrama, acompañado de Rubén Díaz, Manuel Molina y Manuel Luque, pusieron el broche de oro al festival granadino.

Tomado del diario: GRANADA HOY, de España, 9 Agosto, 2019

\section{El Instituto de Investigaciones y Acción Social Martin Luther King de la Universidad} Politécnica de Nicaragua (UPOLI), se une, de manera jubilosa, a este merecido homenaje a la Dra. Magallón, con quien nos une fuerte lazos de cooperación, intercambio y afecto, los cuales extendemos a los colegas miembros de la Fundación Seminario de Investigación para la Paz (SIP). 


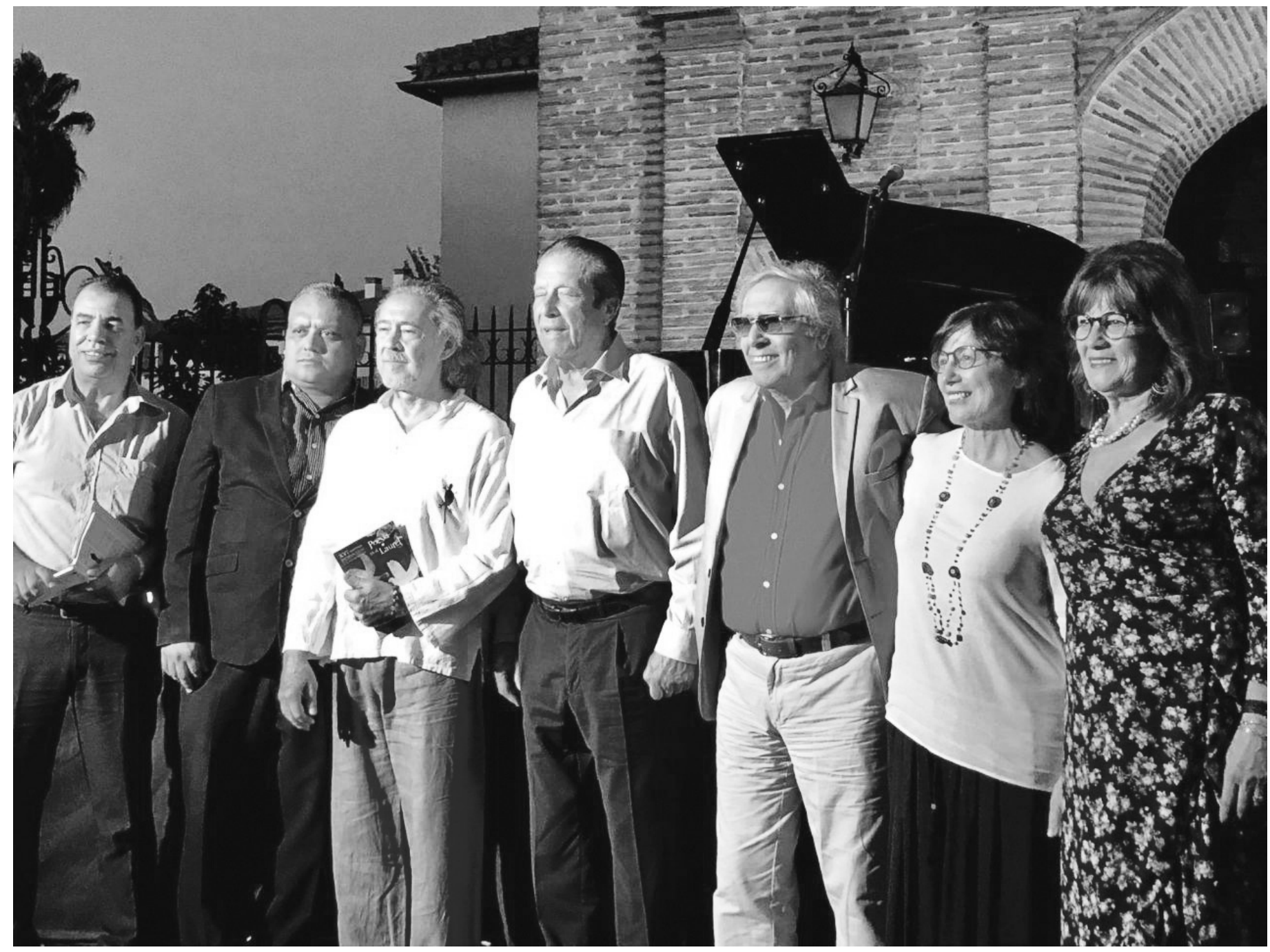

Magnífico el Festival de Poesía en el Laurel, organizado por el Ayuntamiento de La Zubia, al ladito de Granada, con su concejala de Cultura, Rosa Gamero (escultora, $1^{\circ}$ a la derecha) y dirigido por el poeta Pedro Enríquez (3० izda) Con Federico Mayor Zaragoza, Director General de la UNESCO (1987-1999) y los poetas Moez Akaichi (Túnez), Porfirio Salazar (Panamá) y Norberto Barleand....Cada año se articula en torno a un tema. Este año era 'la paz'

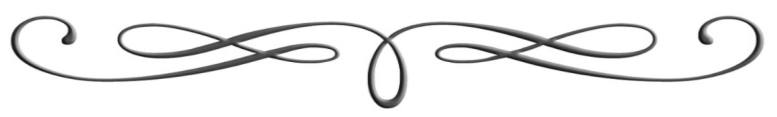

